PEREIRA, J.E.S.; FRANÇA, R.B.; DANTAS, A.C.M.; FORTES, G.R.L. Influência do número de gemas, presença ou ausência de folhas e posição do explante na multiplicação in vitro da batata. Horticultura Brasileira, Brasília, v.23, n.1, p.86-89, jan.-mar. 2005.

\title{
Influência do número de gemas, presença ou ausência de folhas e posi- ção do explante na multiplicação in vitro da batata
}

\author{
Jonny Everson S. Pereira ${ }^{1}$; Rosilene B. de França ${ }^{2}$; Adriana Cibele de M. Dantas ${ }^{3}$; Gerson R.L. Fortes ${ }^{4}$ \\ ${ }^{1}$ Embrapa Acre, C. Postal 321, 69908-970 Rio Branco-AC; Email: jonny@cpafac.embrapa.br; ${ }^{2}$ Universidade Federal de Pelotas, Depto. \\ Fisiologia Vegetal, C. Postal 354, 96001-970 Pelotas-RS; ' ${ }^{3}$ nniversidade Federal de Santa Catarina, CCA, Rod. Admar Gonzaga, 1346, \\ 88034-090 Florianópolis-SC; ${ }^{4}$ Embrapa Recursos Genéticos e Biotecnologia, C. Postal 02372, 70770-900 Brasília-DF
}

\section{RESUMO}

Avaliou-se a posição, presença ou ausência de folhas e número de gemas iniciais do explante na multiplicação in vitro da batata. $\mathrm{O}$ meio de cultura foi formado pelos sais e vitaminas de MS, acrescido de $100 \mathrm{mg} \mathrm{L}^{-1}$ de mio-inositol, $30 \mathrm{~g} \mathrm{~L}^{-1}$ de sacarose e $6 \mathrm{~g} \mathrm{~L}^{-1}$ de ágar. Utilizaram-se diferentes tipos de segmentos nodais (basais e apicais, com e sem folhas, contendo uma, duas e três gemas axilares). Após a inoculação o material foi mantido em sala de crescimento com temperatura de $25 \pm 2^{\circ} \mathrm{C}$, fotoperíodo de 16 horas e $19 \mu \mathrm{E} \mathrm{m}^{-2} \mathrm{~s}^{-1} \mathrm{de}$ irradiância por 32 dias. Para altura e número médio de brotações regeneradas, os melhores resultados foram obtidos com explantes oriundos da posição basal e com três gemas axilares. A taxa de multiplicação do material em cultivo foi maior nos explantes inoculados inicialmente com uma única gema, independentemente da posição do explante ser basal ou apical e, somente nos explantes basais a presença de folhas proporcionou taxa de multiplicação significativamente superior ao apical. Conclui-se que quando se trabalha com material vegetal heterogêneo, sob condições in vitro, as características iniciais dos explantes podem provocar variações na resposta final, causando erros na estimativa da multiplicação.

Palavras-chave: Solanum tuberosum L., micropropagação, crescimento, tipo de explante.

\section{ABSTRACT}

Influence of bud numbers, presence or absence of leaves and explant position on the in vitro multiplication of potato

The position, presence or absence of leaves and bud numbers of the explant were evaluated on the in vitro multiplication of potatoes. The culture medium was constituted by salts and vitamins of MS, added with $100 \mathrm{mg} \mathrm{L}^{-1}$ myo-inositol, $30 \mathrm{~g} \mathrm{~L}^{-1}$ sucrose and $6 \mathrm{~g} \mathrm{~L}^{-1}$ agar. Different types of nodal segments were used (basal and apical, with and without leaves, having, one, two and three axillary buds). The material was maintained in growth room at $25 \pm 2^{\circ} \mathrm{C}, 16$ hours photoperiod and $19 \mu \mathrm{E} \mathrm{m}^{-2} \mathrm{~s}^{-1}$ irradiance during 32 days. For height and number of regenerate sprouts, the best results were obtained with explants originating from the basal position and with three axillary buds. The multiplication rate was higher in explants with a single bud independently of the position. Only in basal explants the presence of leaves improved the multiplication rate. We concluded that, when heterogeneous explants are used the initial characteristics of the explants can promote variation in the final answer and cause mistakes in the development of the in vitro material.

Keywords: Solanum tuberosum L., micropropagation, growth, explant type.

\section{(Recebido para publicação em 18 de fevereiro de 2004 e aceito em 16 de novembro de 2004)}

\begin{abstract}
A batata (Solanum tuberosum) é uma das mais importantes oleráceas cultivadas no Brasil, com área plantada em torno de 182.000 hectares e produção ao redor de 2,7 milhões de toneladas (Choer, 2003). Um dos fatores mais limitantes para a cultura é sua alta suscetibilidade a doenças, especialmente as viroses. Por tratar-se de uma espécie propagada vegetativamente por meio de tubérculos-semente, uma vez infectado, o material propagativo poderá transmitir doenças para as próximas gerações de cultivo, contribuindo para o processo de degenerescência e causando diminuição do vigor e produtividade das cultivares (Lopes e Reifschneider, 1999; Fortes e Pereira, 2003). Portanto, a utilização de material propagativo de alta qualidade genética e fitossanitária para instalação das lavouras, constituise como requisito indispensável para a
\end{abstract}

melhoria do desenvolvimento da cadeia produtiva da batata.

Neste sentido, a micropropagação de plantas vem sendo aplicada rotineiramente a um grande número de espécies de importância econômica, como a batata, e representa uma das formas mais viáveis de propagar plantas isentas de viroses. Contudo, os resultados são muitas vezes divergentes e nem sempre é possível a reprodução dos mesmos pelo fato de que a cultura de tecidos, como técnica de propagação vegetativa, necessita que seja adaptada às necessidades de cada espécie e cultivar, pois estas diferem geneticamente entre si, podendo apresentar resultados diferentes sob as mesmas condições de cultivo (Pereira e Fortes, 2003).

Uma das possíveis causas nas diferenças de resultados obtidos para variáveis como a capacidade de regeneração e multiplicação das espécies in vitro pode ser explicada pelo tipo de explante utilizado e, de acordo com Pierik (1990), são comuns os efeitos da posição e idade dos explantes sobre o processo da regeneração e multiplicação. San-José et al. (1988), verificaram que explantes de segmentos nodais produziram mais parte aérea do que explantes apicais em diversos clones de carvalho. Em macieira (Pereira e Fortes, 2001) e em batata (Campos, 1995; Pereira e Fortes, 2000) também foi demonstrado que a característica inicial dos explantes influencia a regeneração e multiplicação in vitro desses cultivos. Desta forma, a homogeneidade dos explantes no momento inicial do cultivo é de fundamental importância na precisão da estimativa de multiplicação.

Embora existam inúmeros trabalhos relacionados à melhoria do processo de 
multiplicação in vitro de diferentes espécies de plantas (Levin et al., 1997; Guerra et al., 1999; Lorenzo et al., 1998; Pereira e Fortes, 2003), em batata são poucos os relatos que mencionam a influência das características iniciais dos explantes sobre o desenvolvimento e multiplicação in vitro.

O presente trabalho teve por objetivo, avaliar o desenvolvimento e rendimento in vitro de plântulas de batata (altura de brotações, taxa de multiplicação e número de brotações secundárias), cv. Baronesa, em razão das características iniciais dos explantes (número de gemas, presença ou ausência de folhas e posição do explante sobre o meio de cultura).

\section{MATERIAL E MÉTODOS}

Brotações de batata, cultivar Baronesa (Solanum tuberosum, L.), oriundas da multiplicação in vitro, foram separadas em explantes contendo uma, duas ou três gemas axilares. Para verificar o potencial organogênico dos explantes de diferentes partes da planta, as brotações foram divididas em duas partes, sendo assim classificadas como basais ou apicais, na presença e ausência de folhas.

O delineamento experimental utilizado foi em blocos casualizados, contendo cinco repetições, sendo cada parcela formada por cinco explantes. Os tratamentos seguiram esquema fatorial $2 \times 2 \times 3$, com explantes de duas posições da planta (basal e apical), na ausência e presença de folhas e com uma, duas e três gemas axilares.

Os explantes foram cultivados em meio de cultura formado pelos sais e vitaminas de MS (Murashige e Skoog, 1962), adicionado de $100 \mathrm{mg} \mathrm{L}^{-1}$ de mioinositol, $30 \mathrm{~g} \mathrm{~L}^{-1}$ de sacarose e $6,0 \mathrm{~g} \mathrm{~L}^{-1}$ de ágar. Antes da autoclavagem (15 minutos a $121^{\circ} \mathrm{C}$ e $\left.1,5 \mathrm{~atm}\right), \mathrm{o} \mathrm{pH}$ do meio de cultura foi ajustado para $5,8 \pm 0,1$.

Utilizaram-se frascos com capacidade para $250 \mathrm{ml}$, contendo $40 \mathrm{ml}$ de meio de cultura. As condições de cultivo fornecidas foram: fotoperíodo de 16 horas, irrradiância de $19 \mu \mathrm{E} \mathrm{m}^{-2} \mathrm{~s}^{-1} \mathrm{e}$ temperatura de $25 \pm 2^{\circ} \mathrm{C}$.

Após 32 dias de cultivo, a altura e número de brotações regeneradas, além da taxa de multiplicação do material em cultivo foram avaliados. A determina-

Tabela 1. Influência do número de gemas (1;2 ou 3) e da posição do explante (basal ou apical) sobre a altura das brotações, taxa de multiplicação e número de brotações secundárias durante a multiplicação in vitro da batata, cv. Baronesa. Pelotas, Embrapa Clima Temperado, 2000.

\begin{tabular}{|c|c|c|c|c|c|c|}
\hline \multirow{2}{*}{$\begin{array}{l}\mathrm{N}^{\circ} \text { gemas } / \\
\text { explante }\end{array}$} & \multicolumn{2}{|c|}{$\begin{array}{l}\text { Altura das brotações } \\
(\mathrm{cm})\end{array}$} & \multicolumn{2}{|c|}{ Taxa de multiplicação } & \multicolumn{2}{|c|}{$\begin{array}{l}\mathrm{N}^{\circ} \text { de brotações } \\
\text { secundárias }\end{array}$} \\
\hline & Basal & Apical & Basal & Apical & Basal & Apical \\
\hline 1 & $3,2 \mathrm{cA}$ & $2,6 \mathrm{cB}$ & $8,2 a A$ & $8,0 \mathrm{aA}$ & $0,5 \mathrm{cA}$ & $0,1 \mathrm{aB}$ \\
\hline 2 & $4,1 \mathrm{bA}$ & $2,9 b B$ & $5,3 b A$ & $3,9 b B$ & $1,5 b A$ & $0,2 \mathrm{aB}$ \\
\hline 3 & $4,4 a A$ & $3,4 \mathrm{aB}$ & $4,2 \mathrm{cA}$ & $2,7 \mathrm{cB}$ & $2,1 \mathrm{aA}$ & $0,2 \mathrm{aB}$ \\
\hline CV (\%) & \multicolumn{2}{|c|}{15,2} & \multicolumn{2}{|c|}{10,4} & \multicolumn{2}{|c|}{11,8} \\
\hline
\end{tabular}

Médias seguidas por letras distintas, minúsculas na vertical e maiúsculas na horizontal, diferem entre si pelo teste de Duncan em nível de 5\% de probabilidade.

ção da altura das brotações foi realizada medindo-se a porção compreendida entre a região do colo e a inserção da última folha. A taxa de multiplicação foi obtida por meio da relação número de gemas finais/número de gemas iniciais do explante no início do cultivo.

Os dados foram submetidos à análise de variância e a comparação de médias foi realizada pelo teste Duncan em nível de $5 \%$ de probabilidade. Dados referentes à taxa de multiplicação $(\mathrm{x})$ foram transformados segundo $(\mathrm{x}+0,5)^{0,5}$ e sobre altura de brotações não foram transformados. Utilizou-se nas análises o Sistema de Análise Estatística Sanest (Zonta e Machado, 1984).

\section{RESULTADOS E DISCUSSÃO}

Verifica-se que a altura média das brotações regeneradas foi maior quando utilizou-se explantes oriundos da posição basal e com três gemas axilares (Tabela 1). Explantes com estas características proporcionaram brotações que atingiram altura média de 4,4 cm, significativamente superior àquela originada de explantes com uma $(3,2 \mathrm{~cm})$ ou duas gemas $(4,1 \mathrm{~cm})$. Para os explantes da posição apical, também observou-se que aqueles inicialmente inoculados com três gemas proporcionaram brotações significativamente maiores. No entanto, independentemente do número de gemas iniciais no explante, os de origem basal sempre apresentaram brotações significativamente maiores quando comparadas às de origem apical.

Embora não se tenha realizados estudos mais aprofundados, uma das hipóteses sugeridas para explicar tais re- sultados possivelmente estejam relacionados a fatores nutricionais do explante. Normalmente, porções basais são mais engrossadas, apresentando maior quantidade de reservas acumuladas em seus tecidos (Cappelades et al., 1991; Pereira et al., 2001), fato que poderia levar as brotações regeneradas a se utilizar destas reservas para sustentar seu crescimento inicial. Além disso, os explantes inoculados inicialmente com três gemas, apresentavam tamanho superior àqueles com duas ou uma gema vegetativa, ou seja, com maior conteúdo de reservas para promover o crescimento das brotações.

Comportamento semelhante ao obtido para altura de brotações foi observado para o número de brotações secundárias regeneradas, com exceção dos explantes de origem apical, os quais, independentemente do número de gemas, não apresentaram diferenças significativas para o número de brotações (Tabela 1).

Embora para altura e número de brotações secundárias os explantes com três gemas tenham proporcionado os melhores resultados, observou-se que a taxa de multiplicação do material em cultivo foi maior nos explantes inoculados inicialmente com uma única gema, independentemente da posição do explante ser basal ou apical. Estes resultados estão de acordo com aqueles obtidos por Pereira e Fortes (2000) que, trabalhando com o clone de batata C1290-5-82, verificaram que apesar do bom crescimento das brotações a partir de explantes iniciais com três gemas, este tipo de explante proporcionou taxas de multiplicação praticamente $50 \%$ inferiores àquelas obtidas de explantes 
Tabela 2. Influência do número de gemas $(1,2$ ou 3$)$ e da presença ou ausência de folhas no explante sobre a altura das brotações, taxa de multiplicação e número de brotações secundárias durante a multiplicação in vitro da batata, cv. Baronesa. Pelotas, Embrapa Clima Temperado, 2000.

\begin{tabular}{|c|c|c|c|c|c|c|}
\hline \multirow{2}{*}{$\begin{array}{l}\mathrm{N}^{\circ} \text { gemas } / \\
\text { explante }\end{array}$} & \multicolumn{2}{|c|}{$\begin{array}{l}\text { Altura das brotações } \\
(\mathrm{cm})\end{array}$} & \multicolumn{2}{|c|}{ Taxa de multiplicação } & \multicolumn{2}{|c|}{$\begin{array}{c}\mathrm{N}^{\circ} \text { de brotações } \\
\text { secundárias }\end{array}$} \\
\hline & com folha & sem folha & com folha & sem folha & com folha & sem folha \\
\hline 1 & $3,0 \mathrm{cA}$ & $2,8 \mathrm{bA}$ & $8,2 a A$ & $8,1 \mathrm{aA}$ & $0,2 \mathrm{bA}$ & $0,3 \mathrm{bA}$ \\
\hline 2 & $3,5 \mathrm{bA}$ & $3,4 \mathrm{aA}$ & $4,9 b A$ & $4,4 \mathrm{bA}$ & $0,9 a A$ & $0,6 a A$ \\
\hline 3 & $4,3 a \mathrm{~A}$ & $3,5 \mathrm{aB}$ & $3,6 \mathrm{cA}$ & $3,4 \mathrm{cA}$ & $1,3 a A$ & 1,3aA \\
\hline CV (\%) & \multicolumn{2}{|c|}{15,2} & \multicolumn{2}{|c|}{10,4} & \multicolumn{2}{|c|}{11,8} \\
\hline
\end{tabular}

Médias seguidas por letras distintas, minúsculas na vertical e maiúsculas na horizontal, diferem entre si pelo teste de Duncan em nível de $5 \%$ de probabilidade.

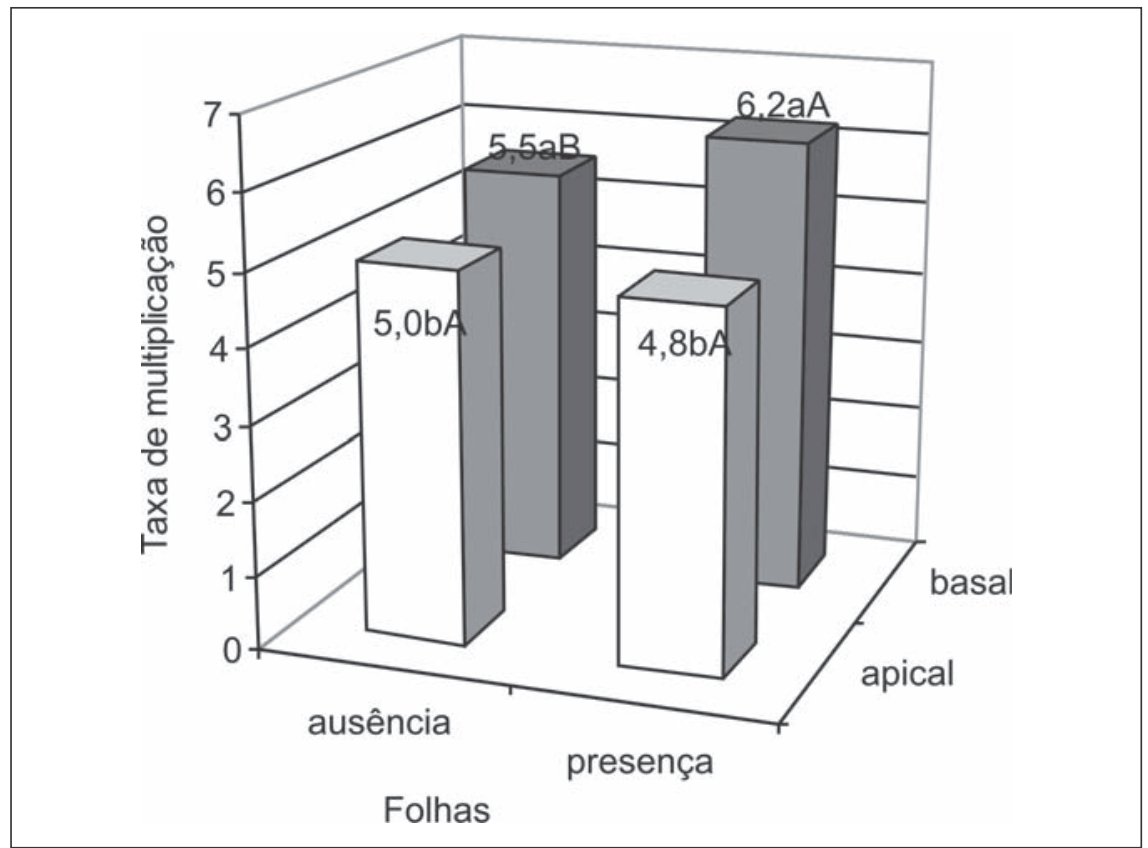

Figura 1. Influência da presença ou ausência de folhas e da posição do explante (basal ou apical) sobre a taxa de multiplicação in vitro da batata, cv. Baronesa. Pelotas, Embrapa Clima Temperado, 2000 (Médias seguidas pela mesma letra, maiúscula na horizontal e minúscula na vertical, não diferem entre si a 5\% de significância pelo teste Duncan).

inoculados com uma única gema. Apesar de não se ter observado diferenças significativas quanto a posição dos explantes com uma gema, naqueles com duas ou três gemas, a posição basal proporcionou maior taxa de multiplicação quando comparada àquelas da posição apical (Tabela 1).

Vários autores têm descrito que são comuns os efeitos da posição dos explantes sobre o desenvolvimento in vitro de espécies vegetais (San-José et al., 1988; Pierik, 1990; Grattapaglia e Machado, 1998). O isolamento e subdivisão das partes aéreas em explantes axilares e apicais podem introduzir uma fonte de variação como resultado da posição original da gema em cultura. A exemplo disso, pode ser citado o trabalho realizado por Pereira e Fortes (2001), onde as brotações de macieira produzidas in vitro foram maiores em número e tamanho quando utilizados explantes oriundos da posição basal. Em batata, as diferenças proporcionadas pelo tipo de explante em cultura, também já foram observadas. Estudos de regeneração in vitro mostraram que explantes de origem apical são os mais indicados quando se quer maior número de explantes regenerados (Campos, 1995; Pereira e Fortes, 2000).
De modo geral, a presença ou ausência de folhas nos explantes não proporcionou melhoras significativas tanto na taxa de multiplicação como no número de brotações secundárias (Tabela 2). A presença de folhas somente proporcionou melhora nos resultados para altura das brotações, nos explantes inoculados inicialmente com três gemas. Para este tipo de explante, as plântulas apresentaram altura média de $4,3 \mathrm{~cm}$, significativamente maior aos inoculados sem folhas que apresentaram altura média de $3,5 \mathrm{~cm}$ aos 32 dias de cultivo.

Nos explantes com folhas a altura das brotações foi maior quanto maior o número de gemas no explante inicial. Nos explantes sem folhas, também foi observada esta tendência, embora explantes com duas ou três gemas não tenham apresentado diferenças significativas para esta variável (Tabela 2). Outra característica importante a ser observada durante a micropropagação, refere-se ao tamanho do explante. Explantes pequenos, normalmente apresentam crescimento mais lento quando comparados a explantes maiores (Grattaplaglia e Machado, 1998; Pereira et al., 2000). Desta forma, é bastante provável que os resultados obtidos para altura de brotações e número de brotações secundárias neste trabalho possam ter sido devido a este fator, visto que explantes inoculados com uma única gemas apresentavam tamanho menor do que aqueles inoculados inicialmente com duas ou três gemas.

Embora o maior número de gemas no explante inicial tenha melhorado a altura de plântulas e o número de brotações secundárias, para taxa de multiplicação observou-se que os melhores resultados foram obtidos com explantes de uma gema, independentemente da presença ou não de folhas no explante inicial. Assim, a taxa de multiplicação média para este tipo de explante foi praticamente 1,8 e 2,3 superior aqueles explantes inoculados inicialmente com duas ou três gemas, respectivamente (Tabela 2). Tais resultados estão de acordo com os obtidos por Pereira et al. (2000).

A avaliação da presença ou ausência de folhas e da posição do explante sobre a multiplicação pode ser observada na Figura 1. De modo geral, explantes 
de origem basal apresentaram resultados significativamente superiores para esta variável quando comparados com os apicais tanto em explantes com ou sem folhas. Apesar de para algumas espécies de plantas, a presença de folhas proporcionar melhorias nas respostas organogenéticas in vitro, por tratar-se de uma fonte de hormônios para o explantes (Mercier et al., 2003), quando avaliados os resultados da presença ou ausência de folhas dentro de cada posição do explante, verificou-se que somente nos explantes basais a presença de folhas proporcionou taxa de multiplicação significativamente superior, pois nos explantes apicais, a presença ou ausência de folhas no explante inicial não influenciou significativamente na taxa final de multiplicação.

Conclui-se que em batata as características dos explantes podem ser importantes fontes de variação, provocando erros nos parâmetros a serem avaliados, caso trabalhe-se com material inicial heterogêneo. Microestacas com mais de uma gema inicial proporcionam a regeneração de brotações maiores, sem no entanto, aumentar a taxa de multiplicação do material. A presença ou ausência de folhas nos explantes não é um fator limitante para que se obtenha os melhores resultados in vitro com a cultura, embora microestacas de origem basal proporcionem resultados superiores aos apicais, especialmente para altura de brotações, taxa de multiplicação e número de brotações secundárias formadas.

\section{LITERATURA CITADA}

CAMPOS, M.A. Sistema de transformação de batata (Solanum tuberosum L.) cultivar Baronesa mediado por Agrobacterium tumefasciens. 1995. 93 f. (Tese mestrado) - FAEM, UFPel, Pelotas.

CAPPELADES, M.; LEMEUR, R.; DEBERGH, P. Effects of sucrose on starch acumulation and rate of photosyntesis in Rosa cultured in vitro. Plant Cell,1 Tissue and Organ Culture, v.25, n.1, p.21-26, 1991.

CHOER, E. Origem e Evolução. In: PEREIRA, A.S.; DANIELS, J. (Eds.). O cultivo da batata na região sul do Brasil. Brasília: Embrapa, DF : Embrapa Informação Tecnológica, 2003. p.57-68. GUERRA, M.P.; DAL VESCO, L.L.; PESCADOR, R.; SCHUELTER, A.R.; NODARI, R.O. Estabelecimento de um protocolo regenerativo para a micropropagação do abacaxizeiro. Pesquisa Agropecuária Brasileira, Brasília, v.34, n.9, p.1557-1563, 1999.

FORTES, G.R.L.; PEREIRA, J.E.S. Batata-semente Pré-básica: Cultura de Tecidos. In: PEREIRA, A.S.; DANIELS, J. (Eds.). O cultivo da batata na região sul do Brasil. Brasília: Embrapa, DF : Embrapa Informação Tecnológica, 2003. p.421-433.

GRATTAPAGLIA, D; MACHADO, M.A Micropropagação. In: TORRES, C.; CALDAS, L.S.; BUSO, J.A. (Eds.). Cultura de tecidos e transformação genética de plantas. Brasília: Embrapa: SPI, 1998. p.183-260.

LEVIN, R.; ALPER, Y.; STAV., R.; WATAD, A. Methods and apparatus for liquid media and semiautomated micropropagation. Acta Horticulturae, v.447, p.659-663, 1997.

LOPES, C.A.; REIFSCHNEIDER, F.J.B. Manejo integrado das doenças da batata. Informe Agropecuário, Belo Horizonte, v.20, n.197, p.5660, 1999.

LORENZO, J.C.; GONZALES, B; ESCALONA, M.; TEISSON, C.; ESPINOSA, P.; BORROTO, C.G. Sugar cane shoot formation in an improved temporary immersion system. Plant Cell, Tissue and Organ Culture, v.54, n.3, p.197-200, 1998.
MERCIER, H.; SOUZA, B.M.; KRAUS, J.E.; HAMASAKI, R.M.; SOTTA, B. Endogenous auxin and cytokinin contents associated with shoot formation in leaves of pineapple cultured in vitro. Brazilian Journal of Plant Physiology, v.2, n.15, p.107-112, 2003.

MURASHIGE, T.; SKOOG, F. A revised medium for rapid growth and bioassays with tobacco tissue cultures. Physiologia Plantarum, v.15, p.473-497, 1962.

PEREIRA, J.E.S.; FORTES, G.R.L. Protocolo para a produção de material propagativo de batata em meio líquido. Pesquisa Agropecuária Brasileira, Brasília, v.38, n.9, p.1035-1043, 2003.

PEREIRA, J.E.S.; FORTES, G.R.L. Multiplicação e aclimatização da macieira influenciada pelo tipo de explante e pelo tempo de permanência em meio de cultura de enraizamento. Revista Brasileira de Fruticultura, Jaboticabal, v.23, n.2, p.417420, 2001.

PEREIRA, J.E.S.; FORTES, G.R.L. Avaliação da posição dos explantes e diferentes concentrações de BAP na regeneração in vitro da batata. Horticultura Brasileira, Brasília, v.18, suplemento, p.177-178, 2000.

PEREIRA, J.E.S.; FORTES, G.R.L.; SILVEIRA, A.O. Influência do número de gemas e da posição de inoculação dos explantes sobre a multiplicação in vitro da batata. Horticultura Brasileira, Brasília, v.18, suplemento, p.179-180, 2000.

PIERIK, R.L.M. Cultivo in vitro de las plantas superiores. Madri: Mundi Prensa, 1990. 326 p.

SAN-JOSÉ, M.C.; BALLESTER, A.; VIEITEZ, A.M. Factors affecting "in vitro" propagation of Quercus robus L. Tree Physiology, v.4, p.281-290, 1988.

ZONTA, E.P.; MACHADO, A.A. SANEST - Sistema de Análise Estatística para microcomputadores. Pelotas: UFPel, SEI, 1984, $138 \mathrm{p}$. 